\title{
EFFICACY OF RAGATHERAPY IN ENHANCING WELL-BEING
}

\section{JYOTILUXMITRIPATHI \&Dr. SEEMA SINGH}

PhD Scholar, Amity University, Noida, India

Assistant Professor, Amity University, Noida, India

\begin{abstract}
Wellbeing in a very simple language can be defined as "the state of being comfortable, healthy, or happy". This state is getting disturbed very often because of our desires, expectations and aspirations thereby making us prone to various psychological and physical disorders. Various researches revealed music has an intense influence on mind and body. Music endorses emotional well-being and positive mental health. It reestablishes, keeps up and enhances enthusiastic, physiological and mental wellbeing. The aim of the present research paper is to discuss the effect of ragatherapy on wellbeing. Raga is the series of choice notes (swaras) that loan a fitting 'state of mind' or feeling in a particular mix. Ragatherapy means healing through the raga. Performing or tuning in to a raga at the best possible dispensed time can influence wellbeing of individuals. Ragatherapy can act as an effective remedy for the emerging issue of wellbeing. The present paper is an attempt to discuss the efficacy of ragas on well-being.

KEYWORDS: Raga, Raga therapy\& Well-being
\end{abstract}

Received: May 26, 2020; Accepted: Jun 16, 2020; Published: Jun 30, 2020; Paper Id.: IJMPERDJUN2020263

\section{INTRODUCTION}

Wellbeing simply means what is good for you. It can be defined as "the state of being comfortable, healthy, or happy". According to McNulty (2012) $)^{[1]}$ "well-being is an important factor in subjective experience, as well as contentment, satisfaction with the past, optimism for the future and happiness in the present". McNulty further argues that, "well-being is not determined solely by people's psychological characteristics but instead is determined jointly by the interplay between those characteristics and qualities of people's social environments".

At the point when individuals experience well-being, they are encountering a feeling of emotional independence - there is nothing negative that is keeping them away from encountering positive feelings.

Tanir, M. and Brett, $\mathrm{F}^{[2]}$ stated "Well-being is often equated with the experience of pleasure and the absence of pain over time". The less psychological pain an individual is experiencing the more he or she is going to experience well-being. When somebody is experiencing wellbeing they are likewise encountering a few different things. It includes a feeling of self-fulfillment, which is the sentiment being cheerful and fulfilled on the grounds that one is accomplishing something that completely uses one's capacities and gifts. The sentiment having a reason in life and association with others are likewise supporters to well-being ${ }^{[2]}$. When individuals feel as if they have a purpose on the planet, they have a feeling that they have a place. They sense that they matter.

\section{HOLISM MODEL OF WELLBEING}

According to Holism Model, well-being lies in four components: physical, emotional, spiritual and psychological ${ }^{[3]}$. A state of complete wellbeing is achieved when a person is stable in all four components. 
2.1 Physical well-being: A condition of physical wellbeing is not just the lack of ailment. It incorporates way of life conduct decisions to guarantee wellbeing, maintain a strategic distance from preventable infections and conditions, and to live in an adjusted condition of body, brain, and soul ${ }^{[4]}$.

2.2 Emotional Wellbeing:Emotional wellbeing is not the lack of feelings, but rather it is one's capacity to comprehend the estimation of his/her feelings and utilize them to propel his/her life in positive directions.Emotional well-being is a level of mental prosperity, or a nonappearance of dysfunctional behavior.It is the "mental condition of somebody who is working at an agreeable level of enthusiastic and behavioral modification". From the viewpoint of positive brain science or comprehensive quality, emotional wellness may incorporate an individual's capacity to appreciate life, and make a harmony between life exercises and endeavors to accomplish mental flexibility.

2.3 Spiritual wellbeing: Spiritual wellbeing is a private matter comprising of values and beliefsthat deliver a purpose in one's life. However different entities might have diverse opinions about spiritualism, it is usually reflected to be the quest for meaning and purpose in human life, leading one to endeavor for a state of congruence with oneself and others while functioning to harmonize inner needs with the rest of the world.

2.4 Psychological wellbeing: Carol Ryff has theorized psychological wellbeing as comprising of 6 dimensions: autonomy, environmental mastery, personal growth, positive relations with others, purpose in life, self-acceptance.As per the World Health Organization (WHO), psychological wellness incorporates "subjective prosperity saw self-viability, selfsufficiency, skill, between generational reliance, and self-realization of one's scholarly and enthusiastic potential, among others" ${ }^{[5]}$.

\section{TRIPARTITE MODEL OF WELLBEING}

The tripartite model of mental well-being is a standout amongst the most far reaching models of well-being in psychology. This model perspectives mental well-being as having three segments of hedonic (or subjective), psychological, and social well-being. Hedonic well-being concerns emotional aspects of well-being, however psychological and social well-being concerns skills, abilities, and optimal functioning ${ }^{[6]}$.

\section{Music}

Music has a profound effect on body, mind and spirit. It synchronizes brain waves, modifies behaviour and stimulates physiological responses. More to the point, it is fruitful in decreasing anxiety, pain, fear, depression, and boosts self-esteem and the immune system ${ }^{[7]}$.Music has arisen as an essential part of therapeutic practice in the most recent century. It has constantly been a piece of our human progress, regardless of whether in sanctuary rituals or as bedtime songs.Music, in the old world, was accepted to be a capable apparatus of piety and healing.

Music therapy is a scientific technique for effective cures of ailment through the use of music. Numerous reviews have researched the advantages of music in different illnesses. After stroke, for example, music has been appeared to improve cognitive recovery, improve auditory and verbal memory, attention and mood in patients ${ }^{[8]}$. Amid medical techniques, music has been accounted for relaxation; lessen anxiety in patients before, after and amid the method. The vast majority of these reviews were embraced utilizing Western music. Just a couple studies have explored the advantages of Indian classical music (ragas) ${ }^{[9,10,11]}$. 


\section{VEDIC HISTORY OF MUSIC}

Vedic customs going back approximately 5000 years prior had an extraordinary instinct about the force of sound and inflection. The Vedic serenades and music which had more sound and rhthym, utilized as a wellspring of mending and upliftment mirrored the instinct that every pitch and expression of voice could have valuable or unfavorable impacts ${ }^{[12]}$. The Vedic serenades were utilized by the general population to satisfy the managing divinities of various Vedic penances to get invocations of splendor, power and knowledge to cure infections. Phrases from Atharva Veda ${ }^{[13]}$ showed that going with the drinking of different things in a mending function amid Vedic circumstances, Vedic hymns were additionally utilized against illness emerging from terrible changes of wind, bile or phlegm and for paying praise to lightning imagined as the reason for fever, headache and cough, to discharge the sufferer from migraine and cough.

Present day music therapy exercise includes utilization of archika, gathika and samika verses (Vedic verses with single, two and three notes respectively) to boost centered attention and to enhance concentration and to help get into contemplative and tranquil states. These presentations called proto ragas are utilized as a part of a custom curriculum setting for kids with exceptional needs during the time spent mental developments, behavior and personality trait. With these proto-ragas and fast rhythms, special children react promptly and more rapidly than to medium-paced ragas ${ }^{[14]}$.

Ragas have been classified in three groups namely Vata, Pitta and Kapha which notes the effects of raga-s on the human body. Also the swaras are connected with the chakras (different energy centres in the body), cells and nerves and the physiological structure of the human body. Pentatonic ragas have been used for curing diseases, sickness and bad health, hexatonic raga-s to attain beauty, youth and charm and sampoorna ragas (ragas with all the notes) were used for strength, wisdom, wealth, good harvest, prosperity and children.

\section{HISTORICAL BACKGROUND: ORIGINS OF MUSIC}

From exceptionally antiquated circumstances savants like Plato and Confucius have laid accentuation on the requirement for melodic preparing for statesmen ${ }^{[15]}$. Ancient Greeks, Arabs, and Indians were very much aware of the therapeutic property of music, and there are legends affirming the same ${ }^{[16]}$. Hippocratic custom laid accentuation on applying regular techniques for mending in medical practice ${ }^{[17]}$. The first to utilize music's remedial impacts to overcome "passion" was Asclepius ${ }^{[18]}$. Ancient Hindus trusted that distress brought about by man's uncontrolled thinking could be dealt with by music therapy ${ }^{[19]}$. In India, writing on investigation of music (Gandharvatattva) goes back to fourth century B.C ${ }^{[20]}$. "Raga Chikitsa," one of the old writings explains on the helpful part of melodic melodies ${ }^{[21]}$. Swami Haridas, a traditional performer who lived in the sixteenth century, was one of the numerous who utilized music in treating ailments amid long time past times ${ }^{[20,22]}$. A seventeenth century work titled "SangitaSudha" wrote by Nayaka King RaghunathaNayak and his minister GovindaDikshitar gives a record of impacts of music on feelings. Antiquated works gathered by King Sahaji (1684-1711) that have been protected in the ThanjavurSaraswatiMahal Library as palm leaf compositions fill in as a record of medicinal utilization of music in mental ailments ${ }^{[23]}$. The flexibility of character of old individuals as saw by Indian students of history can most likely is credited to the melodic practices of past days ${ }^{[24]}$.

\section{NADAYOGA AND RAGACHIKITSA}

Nada Yoga and Raga Chikitsa structure the foundation of the old arrangement of music treatment, which is exceptionally profound and enhanced with everlasting vitality content. 


\section{Yoga}

Yoga is a Hindu discipline of training the consciousness for a state of perfect spiritual insight and tranquility, a union between the mind, body andthe spirit by creating a balance in the body through developing bothstrength and flexibility through practicing asanas.

\section{Nada yoga}

Nada Yoga is yoga of sound, a path of exploration of consciousnessthrough sounds. Nada, the primordial sound forming the basis of musicevolves in different stages of para, pashyanthi, madhyama and vaikhari.Sundar S., $2007{ }^{[9]}$ stated- from the different energy centres found in the human body and opening up of these seven chakras (energy centres) reflect their physical, psychological and physiological characteristics to reestablish our inner balance restoring health and form. The system involves deep listening to thebody inner sounds and acoustics and music of the external worlds whichare termed as Ahataand Anahata, integrate meditation techniques andcertain hatha yoga practices conductive to sonic exploration. Most of themodern Indian music therapy approaches use Ahata music as a therapeutic and a prophylactic medium in clinical and educational settings.

\section{Nadopasana}

Nadopasanawhich is dedication to music is a path of musical yoga; partand parcel used in religious rites, rituals and sacrifices is considered as amedium of prayer to God, a path, a realization and a medium to seek salvation from the sins committed by one. Sundar, $2006^{[25]}$ indicated that the more cultural andtraditional Indian music had a spiritual influence, which expressed one'sdevotional feelings and might bring comfort, hopes and peace of mind tothe listeners and alleviate pain and anxiety.

\section{Raga chikitsa}

Raga Chikitsa, an extinct sanskrit treatise, as its name implies dealt withcurative ragas and suggested specific ragas with specific therapeutic andmood enhancing characteristics suggested to be used in clinical settingsare still more to be tested and validated ${ }^{[26,27]}$.

\section{Nada Yoga and Raga Chikitsa}

The Law of vibration expresses that everything in the cosmos vibrates ${ }^{[28]}$, which is in consonance with the way of thinking of Nada Yoga ${ }^{[29]}$. The ordinary act of Nada Yoga expanded alpha musicality on electroencephalography and furthermore improved the general well being of the subjects ${ }^{[30]}$. It is additionally compelling in lessening stress ${ }^{\text {[31] }}$. Carnatic melodic preparation significantly affects sound-related transient goals ${ }^{[32]}$. An examination demonstrated that Raga DesiTodi essentially diminished scores on gloom and uneasiness ${ }^{[33]}$.

\section{RAGA THERAPY}

Indian ragas are among the most antiquated and persevering types of music on the planet. Diverse ragas have been routinely known to be related with changing states of mind. Ragatherapy is the knowledge of how to use raga for the purpose of healing ${ }^{[34]}$.

Antiquated Indian music has formulated an uncommon treatment in light of the seventy two ragas. According to an ancient Indian text, "SwaraShastra", the seventy two melakarta (parent) ragas control seventy two important nerves in 
the body. The clarification, pitch, tone and specific course of action of swaras (notes) in a particular raga animates, reduces and fixes various sicknesses activating electro-attractive change in the body. A couple of depictions of the advantages of Indian classical music have turned out to be accessible ${ }^{[35,10,11]}$.

It is suitable to characterize Raga now. Raga is neither song alone, nor notes; neither scale nor mode. It's a group of all these. It is the knowledge of how to use raga for the purpose of healing ${ }^{[34]}$.It's a yoga framework through the vehicle of resonant sounds. It is that sort of sound piece comprising of melodic developments that have the impact of freeing the hearts of men. Hindustani/Classical music considers ragas as depicting specific moods. It is trusted that whosoever sings/plays out a raga bound to the raga determinations (lakshanas) and with excellence in pitch (swarashuddhi) will have finish control on the comparing nerve. Ensembles of raga guarantee a specific encouraging impact on the brain and body. Repetitively attending the specific raga being selected for a specific ailment yields a network of sound vibration which affects the central nervous system.

Matanga (9-10th century AD) was the most punctual essayist to characterize raga. As indicated by him "raga is that kind of sound composition consisting of melodic movements which has the effect of clearing the hearts of men." "There are four cradles of raga: folk songs, poetry, devotional songs of spiritualists and configurations of classical musicians. While melody is the characteristic of Western music, Indian music is immaculate melody. The general term for melody in India is raga or ragini." (KangraRagmala- - M.S. Randhawa). Orchestras of raga have a distinct alleviating impact on the brain and in addition the body ${ }^{[36]}$.

\section{Ragatherapy and Well Being}

Music has been appeared to positively affect wellbeing ${ }^{[37]}$. Music is an effective intervention to promote well being ${ }^{[38]}$. Music appears to have past a cleansing impact. It has been found to reduce sadness by giving new tasteful, physical and social encounters for the patients ${ }^{[39]}$. It can upgrade correspondence and expressive aptitudes, and when utilized enough as an assistant can improve negative side effects and social working in patients experiencing schizophrenia and related issue $^{[40]}$. The one of a kind need of ladies and teenagers experiencing substance use issues can be met by music treatment ${ }^{[41]}$. Introductory discoveries recommend a positive job of music treatment in advanced youths with neurodevelopment delay ${ }^{[42]}$. Music treatment for parents who have a kid with incapacities improves parental psychological well-being and advances positive child-rearing ${ }^{[43]}$. Formative music bunches positively affect the social conduct of untimely and full-term newborn children ${ }^{[4]}$. Music can be seen by people who are hard of hearing by prudence of its visual and vibrotactile modalities ${ }^{[45]}$. Musical preparation can balance age-related intellectual decay ${ }^{[46]}$. Tuning in to music day by day in the first month after stroke prompts basic changes in the frontolimbic district ${ }^{[47]}$, and these progressions were related with improved subjective and enthusiastic recuperation ${ }^{[48]}$. Music-based subjective remediation improves official capacities in patients with awful cerebrum injury ${ }^{[49]}$. Music is successful in mitigating constant torment ${ }^{[50]}$, and is useful in palliative consideration $^{[51]}$. Music can cause a feeling of subjective well-being and positively affect subjective capacity, disposition, and personal satisfaction of older adults ${ }^{[52]}$.

DrVijayalakshmiSubramaniam ${ }^{[53]}$, head of the department of Otorhinolaryngology, Yenepoya Medical College, Mangalore, stated that music promotes wellness and also empowers one to confront and defeat difficulties in life unhesitatingly, while as yet remaining grounded. Music additionally supports resistance. Sickness influences a person's mind and contrarily impacts his/her general wellbeing. At the point when utilized with medication, music fills in as an adjuvant that quiets the psyche and improves by and large wellbeing. 


\section{DISCUSSIONS}

Sound itself is an intense vitality. This sound tuned in to nature assists all the living creatures with attaining true serenity and in people, numerous a times, helps him to look for inside. That is the reason the sound (nothing) is called Brahma i.e. nothing brahma and this craftsmanship is honored by Goddess Saraswati. At the point when this music is played in order and amicability in various structures called as Tala and Raga, it is conceivable to change the mental example and also dispose of the physical sicknesses. Consequently, this sound of music is presently perceived as Music Therapy. In Nature Cure, an illness is because of awkwardness of the PanchaMahabhutas in the body. Thus, when the body and psyche are brought into concordance, the illness/turmoil is cured from the root and not simply smothered. The conventional Classical and Hindustani music follows up on the body, brain and soul of the craftsman furthermore on the audience. A large number of pages have been composed, saying the significance of Indian Music on Mind, Body and Soul and its Healing Nature. Music influences people, as well as creatures and plants as well. It is Yoga in itself.

Listening to great music developsenergy, swiftness, bliss, readiness. Each cell in the body is empowered; there is expanded imperativeness with genuine feelings of serenity. Music can assume a viable part in helping us lead better, productive lives. Listening to particular sorts of music at particular times of the day has been appeared to be useful in keeping up great wellbeing. Indian music, with its numerous Ragas, is known to be especially helpful esteem. The therapeutic force of music radiates from the reverberation of certain ragas on hormonal and glandular capacities which deliver emissions that keep the body adjusted and along these lines recuperates. It is trusted that music fortifies the pituitary organ, whose discharges influence the sensory system and the stream of blood.

Indian fables had a convention of 'Bhajan - Kirtan' on all events of celebrations and customs and so forth. This is a sort of Treatment where music helps one to overlook once life's tasks and strain for couple of hours and he gets invigorated and recuperated because of the energized air and happiness which music brings. Present day prescription had effectively acknowledged the entering force of sound by imagining and consistently utilizing advanced analytic instruments like Ultrasound. Since numerous decades, Film/Cinema tunes have been a wellspring of motivation and tunes have been composed for each event and disposition of the human personality. Unlimited cases of Tansen helping the lights by singing Raga Deepak, numerous cutting edge maestros have cured sicknesses through music. Present day science and prescription are currently rediscovering the recuperating forces of music. Also, music treatment - the specific utilization of music in treating people with exceptional needs in mental and physical wellbeing, restoration and specialized curriculum, is making strides.

Musical experience includes enthusiastic titillations, bringing about the grab of the brain. By occupying the brain from its focus on a torment area (or an excruciating background) music can work like an agony reliever with no reactions. The Raga Research Center in Chennai, India, is as of now making a thorough investigation of Indian ragas and assessing their restorative potential with the assistance of artists, specialists and therapists.

\section{CONCLUSIONS}

Indian music therapy is an integration of ancient healing practices andmusical traditions coupled with the recent modifications derived basedon the modern day practice and the knowledge gained by current clinicalstudies undertaken. Indian music therapy is based on long empirical traditions not proven in the western sense of empiricism but it is unique andis cultural and throws open great scope for further prove and studies. Ragatherapy is effective for mind, body, spirit 
and emotion thereby improving wellbeing. This therapy is a requirement for emotional wellness to equip the comprehensive approach.It can act as an effective remedy for the emerging issue of wellbeing. Hence, a few stages ought to be gone up at individual, organization and group level to illuminate the ideas and make this treatment open to everybody so more individuals may profit. The present paper is an endeavor at this end.

\section{REFERENCES}

1. McNulty JK, Fincham FD. Beyond positive psychology? Toward a contextual view of psychological processes and wellbeing.Am Psychol. 2012 Feb-Mar; 67(2):101-10. doi: 10.1037/a0024572. Epub 2011 Jul 25.

2. Tamir, M., \& Ford, B. Q. (2012a). Should people pursue feelings that feel good or feelings that do good? Emotional preferences and well-being. Emotion, 12, 1061-1070.

3. Bakhtawar Hashwani on June 13, 2016. https://blogs.jpmsonline.com/2016/06/13/music-therapy-a-melody-for-mental-health/

4. Aana, 2020, https://www.aana.com/practice/health-and-wellness-peer-assistance/about-health-wellness/physical-well-being

5. World wellbeing report, 2001. https://www.who.int/whr/2001/en/

6. Joshanloo, M., 2013. Mental well-being in Iran: the importance of comprehensive well being in understanding the linkages of personality and values. In C.L. Keyes (Ed.), Mental well-being: international contributions to the study of subjective wellbeing and positive mental health, pp. 177-207. New York: Springer.

7. Sharma, V., \& Sharma, M. (2012). Raga Therapy: Power of Music to Alleviate Academic Stress in Adolescents. Child and Adolescent Mental Health, 227.

8. Särkämö T, Tervaniemi M, Laitinen S, Forsblom A, Soinila S, Mikkonen M, Autti T, Silvennoinen HM, Erkkilä J, Laine M, Peretz I, Hietanen M., 2008. Music listening enhances cognitive recovery and mood after middle cerebral artery stroke. Brain, 131(Pt 3):866-76. doi: 10.1093/brain/awn013.

9. Sunder S. Traditional healing systems and modern music therapy in India. Music Therapy Today. 2007; 8(3):397-407.

10. Sairam T.V. (2004): Raga Therapy. NADA Centre for Music Therapy Books, Chennai.

11. Raju, MVR. (2009). Health Psychology and Counseling. New Delhi: Discovery Publishing House Pvt. Ltd.

12. Sumathy, Sundar\&Sairam, T.V. (2005). Music Therapy Traditions in India. Voices: A World Forum for Music Therapy. Retrieved from http:// www.voices.no/country/monthindia_march2005.html

13. Whitney, W. (1971). Atharva Veda Samhita (Tr.) Volume I. MotilalBararsidas, New Delhi.

14. Sairam, T.V. (2006). Self-Music Therapy. Nada Centre for Music Therapy, Chennai.

15. Sambamurthy P. 8th ed. Chennai: The Indian Music Publishing House; 2002. South Indian Music. Book V. [Google Scholar]

16. Sairam TV. Can music replace medicine? Bhavan's J. 2015; 61:64-70. [Google Scholar]

17. Gordon JS. Holistic medicine and mental health practice: Toward a new synthesis. Am J Orthopsychiatry. 1990; 60:35770. [ubMed] [Google Scholar]

18. Conrad C. Music for healing: From magic to medicine. Lancet. 2010; 376:1980-1. [ubbed] [Google Scholar]

19. Sairam TV. Reggae in music therapy. Bhavan's J. 2013; 60:94-5. [Google Scholar]

20. Sambamurthy P. 6th ed. Chennai: The Indian Music Publishing House; 1999. South Indian Music. Book 1. [ㅁoogle Scholar]

21. Sairam TV. Music for the emotionally disturbed. Bhavan's J. 2014;61:56-60. [Google Scholar] 
22. Wikipedia contributors. Swami Haridas. Wikipedia, the free encyclopedia. 2015. [Last updated on 2015 Jan 30; Last cited on 2015 Feb 25]. Available from: http://www.en.wikipedia.org/w/index.php?title=Swami Haridas and oldid=644811933.

23. Sairam TV. Music for the emotionally disturbed. Bhavan's J. 2014; 61:56-60. [Google Scholar]

24. Sairam TV. Music therapy for the upwardly mobile. Bhavan's J. 2012; 58:78-81. [Google Scholar]

25. Sundar, Sumathy. (2006). Effects of Music Therapy and Counselling: A case of state anxiety of a ca - hypo pharynx patient. Music Therapy Today (online) Vol. VII (1) 8-29. Available at http://www.Music-TherapyWorld.net

26. Varadalakshmi, K(1948). Raga and Rasa. Thesis submitted for the degree of Master of Letters at University of Madras.

27. Sairam, T.V. (2005). Raga Therapy. Chennai. Nada Centre for Music Therapy.

28. Laws of the Universe. 2015. [Last cited on 2015 Feb 23]. Available from: http://www.lawsoftheuniverse.weebly.com/law-ofvibration.html.

29. Spiteri M. Sanskrit Philosophy of Nada. 2015. [Last cited on 2015 Feb 26]. Available from: http://www.academia.edu/1755288/Sanskrit Philosophy of Nada.

30. Kumar K. Effect of learning music as a practice of Nada Yoga on EEG alpha and general well being. Yoga Mimamsa. 2011;43:215-20. [ Google Scholar]

31. Kumar K. Practice of Nada Yoga to reduce stress. Nat Wealth. 2009:8. [Google Scholar]

32. Mishra SK, Panda MR. Experience-dependent learning of auditory temporal resolution: Evidence from Carnatic-trained musicians. Neuroreport. 2014;25:134-7. [ubMed] [Google Scholar]

33. Gupta U, Gupta BS. Psychophysiological responsivity to Indian instrumental music. Psychol Music. 2005;33:363-72. [ [Google Scholar]

34. Bill Osmer (2006). Raga chikitsa and raga raginividya. http://www.yogatunes.org/hello-world/

35. Sundar, S. (2007). Traditional healing systems and modern music therapy in India. Music Therapy Today (online) Vol. III (3). Available at http://musictherapyworld.net

36. You ZY, Wang JZ. Zhongguoyixuekexueyuanxuebao. (2002). Metaanalysis of assisted music therapy for chronic schizophrenia, Institute of Evidence-Based Medicine, Shandong University, Jinan 250012, China; 24(6), 564-567.

37. MacDonald RA (2013). Music, health, and well-being: A review. Int J Qual Stud Health Well-being; 8:20635. [PMC free article] [PubMed] [Google Scholar]

38. Wall, M., \& Duffy, A. (2010). The effects of music therapy for older people with dementia literature review. British Journal of Nursing, 19(2), 108-113. Retrieved from http://www.internurse.com/cgibin/go.pl/library/abstract.html?uid=46295

39. Maratos A, Crawford MJ, Procter S. Music therapy for depression: It seems to work, but how? Br J Psychiatry. 2011;199:923. [ㅁuMed] [ Google Scholar]

40. Mössler K, Chen X, Heldal TO, Gold C. Music therapy for people with schizophrenia and schizophrenia-like disorders. Cochrane Database Syst Rev. 2011 CD004025. [PubMed] [Google Scholar]

41. Aletraris L, Paino M, Edmond MB, Roman PM, Bride BE. The use of art and music therapy in substance abuse treatment programs. J Addict Nurs. 2014;25:190-6. [PMC free article] [PubMed] [Google Scholar]

42. Pasiali V, LaGasse AB, Penn SL. The effect of musical attention control training (MACT) on attention skills of adolescents 
with neurodevelopmental delays: A pilot study. J Music Ther. 2014;51:333-54. [PubMed] [Google Scholar]

43. Williams KE, Berthelsen D, Nicholson JM, Walker S, Abad V. The effectiveness of a short-term group music therapy intervention for parents who have a child with a disability. J Music Ther. 2012;49:23-44. [ㅁubMed] [ Google Scholar]

44. Walworth DD. Effects of developmental music groups for parents and premature or typical infants under two years on parental responsiveness and infant social development. J Music Ther. 2009;46:32-52. [PubMed] [Google Scholar]

45. Good A, Reed MJ, Russo FA. Compensatory plasticity in the deaf brain: Effects on perception of music. Brain Sci. 2014;4:560-74. [PMC free article] [PubMed] [Google Scholar]

46. Paquette S, MignaultGoulet G. Lifetime benefits of musical training. Front Neurosci. 2014;8:89. [PMC free article] [마.Med] [ Google Scholar]

47. Särkämö T, Ripollés P, Vepsäläinen H, Autti T, Silvennoinen HM, Salli E, et al. Structural changes induced by daily music listening in the recovering brain after middle cerebral artery stroke: A voxel-based morphometry study. Front Hum Neurosci. 2014; 8:245. [PMC free article] [PubMed] [Google Scholar]

48. Särkämö T, Tervaniemi M, Laitinen S, Forsblom A, Soinila S, Mikkonen M, et al. Music listening enhances cognitive recovery and mood after middle cerebral artery stroke. Brain. 2008;131:866-76. [PubMed] [ [Google Scholar]

49. Hegde S. Music-based cognitive remediation therapy for patients with traumatic brain injury. Front Neurol. 2014;5:34. [PMC free article] [PubMed] [Google Scholar]

50. Guétin S, Giniès P, Siou DK, Picot MC, Pommié C, Guldner E, et al. The effects of music intervention in the management of chronic pain: A single-blind, randomized, controlled trial. Clin J Pain. 2012;28:329-37. [PubMed] [Google Scholar]

51. Gutgsell KJ, Schluchter M, Margevicius S, DeGolia PA, McLaughlin B, Harris M, et al. Music therapy reduces pain in

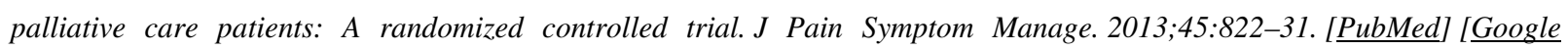
Scholar]

52. Seinfeld S, Figueroa H, Ortiz-Gil J, Sanchez-Vives MV. Effects of music learning and piano practice on cognitive function, mood and quality of life in older adults. Front Psychol. 2013;4:810. [PMC free article] [PubMed] [Google Scholar]

53. Prabhu, U.K. (2019). Raga therapy: Can music really cure mental and physical ailments?

54. https://www.sundayguardianlive.com/culture/raga-therapy-can-music-really-cure-mental-physical-ailments

55. EM, U., AM, A., AE, M., \& ME, U. (2016). Feeding Options and HIV Status of Babies Whose Mothers Were on Antiretroviral Therapy in University of Teaching Hospital, Uyo, Nigeria. International Journal of Medicine and Pharmaceutical Science (IJMPS) ISSN (P), 2250-0049.

56. Sudhakar, S., \& Nathan, C. S. Effects Of Deep Stripping Massage With Eccentric Resistance Versus Static Stretch With Cryotherapy On Improving Calf Muscle Flexibility.

57. Mohamad, S. M. A. A. S., \& Mohammad, Z. Using Expressive Art Therapy In The Healing Process Of Delinquent Adolescents. 

